\title{
Chemosensory Selectivity of Output Neurons Innervating an Identified, Sexually Isomorphic Olfactory Glomerulus
}

\author{
Carolina E. Reisenman, Thomas A. Christensen, and John G. Hildebrand \\ Arizona Research Laboratories, Division of Neurobiology, University of Arizona, Tucson, Arizona 85721-0077
}

The antennal lobe $(\mathrm{AL})$ of insects, like the olfactory bulb of vertebrates, is characterized by discrete modules of synaptic neuropil called glomeruli. In some insects (e.g., moths and cockroaches), a few glomeruli are sexually dimorphic and function in labeled lines for processing of sensory information about sex pheromones. Controversy still exists, however, about whether projection (output) neurons (PNs) of glomeruli in the main AL are also narrowly tuned. We examined this critical issue in the AL of the moth Manduca sexta. We used intracellular recording and staining techniques to investigate the chemosensory tuning of PNs innervating an identifiable, sexually isomorphic glomerulus, G35, in the main AL. We found that the morphological features and chemosensory tuning of G35-PNs were nearly identical in females and males. G35-PNs responded to low concentrations of the plant-derived volatile compound cis-3-hexenyl acetate (c3HA), but the sensitivity threshold of female PNs was lower than that of male PNs. The propionate and butyrate homologs of c3HA could evoke excitatory responses but only at moderate-to-high concentrations. Other plant volatiles did not evoke responses from G35-PNs. Moreover, PNs innervating glomeruli near G35 (in females) showed little or no response to c3HA. Female G35-PNs were hyperpolarized by ( \pm )linalool, a compound that excites PNs in an adjacent glomerulus, thus providing evidence for lateral-inhibitory interactions between glomeruli. Our results show that PNs arborizing in an identified glomerulus in the main olfactory pathway are morphologically and physiologically equivalent in both sexes and have characteristic, limited molecular receptive ranges that are highly conserved across individuals.

Key words: olfactory; glomerulus; chemosensory; microelectrode; odor; intracellular; insect

\section{Introduction}

The antennal lobe $(\mathrm{AL})$, the analog in insects of the olfactory bulb (OB) of vertebrates, contains an orderly array of glomeruli, sites of primary processing of olfactory information. The glomeruli are organized chemotopically [i.e., each glomerulus is a functional unit dedicated to processing information about a particular odor compound or molecular attribute(s) of odor compounds] (for review, see Buck, 1996; Hildebrand and Shepherd, 1997). The mammalian OB includes $>1000$ glomeruli (Mombaerts et al., 1996), whereas the AL of most insects has only $40-$ 160 glomeruli, depending on the species (Flanagan and Mercer, 1989; Rospars and Hildebrand, 1992, 2000; Berg et al., 2002; Masante-Roca et al., 2005). Thus, because of its numerical simplicity and the possibility of identifying glomeruli across individuals, the insect AL is an advantageous model for studies of glo-

Received April 5, 2005; revised July 15, 2005; accepted July 16, 2005.

This work was supported by a fellowship from the Pew Latin American Fellows Program in the Biomedical Sciences of the Pew Charitable Trust (C.E.R.) and by National Institutes of Health Grant R01-DC-02751 (J.G.H.). We thank Heather Stein for invaluable technical assistance and for reconstruction of AL glomeruli using Amira software, Andrew Dacks for critically reading this manuscript, Hong Lei and Pablo Guerenstein for valuable comments, other members of our research group for many helpful discussions, Patty Jansma for advice on confocal microscopy, and Suzanne Mackzum for rearing Manduca sexta. We are grateful to the two anonymous reviewers for their useful comments and suggestions for improvements to this manuscript.

Correspondence should be addressed to Dr. Carolina E. Reisenman, Arizona Research Laboratories, Division of Neurobiology, University of Arizona, P.0. Box 210077, Tucson, AZ 85721-0077. E-mail: carolina@neurobio.arizona.edu.

DOI:10.1523/JNEUROSCI.1314-05.2005

Copyright $\odot 2005$ Society for Neuroscience $\quad 0270-6474 / 05 / 258017-10 \$ 15.00 / 0$ merular function. As in other moths (Vickers et al., 1998; Berg et al., 2002; Masante-Roca et al., 2005), the AL of Manduca sexta (hereinafter referred to as Manduca) includes two olfactory subsystems. One, analogous to the "main" OB of vertebrates, has 60 sexually isomorphic glomeruli that process information about volatile compounds associated with food and possibly other odors. The second subsystem, analogous to the "accessory" OB of many vertebrates (for review, see Brennan and Keverne, 2004), comprises three sexually dimorphic glomeruli (Rospars and Hildebrand, 1992). In males, these specialized glomeruli belong to the macroglomerular complex (MGC), and in females they comprise two large glomeruli [medial and lateral large female glomeruli (LFGs)] and one smaller glomerulus. The dedication of the MGC to processing information about the conspecific female sex pheromone is well established (Christensen and Hildebrand, 1987; Christensen et al., 1989; Hansson et al., 1991, 2003). Similarly, the LFGs might play important roles in the selection of appropriate sites for oviposition. Projection (output) neurons (PNs) with dendritic arborizations restricted to one of these glomeruli, the lateral LFG (latLFG), respond preferentially to the (+) enantiomer of linalool (Reisenman et al., 2004), a plant volatile [Stranden et al. (2003) and references therein]. Little is known, however, about the chemosensory tuning and functional properties of individual PNs in identified, sexually isomorphic glomeruli in the main AL of Manduca or other species. Recent evidence indicates that PNs in a sexually isomorphic glomerulus in Manduca [the labial-palp-pit organ glomerulus (LPOG), 
which processes information about environmental $\left.\mathrm{CO}_{2}\right]$ are also narrowly tuned (Guerenstein et al., 2004b). Our aim in this study was to test whether PNs in the main AL, like those of the LPOG, MGC, and latLFG, of Manduca have limited, characteristic molecular receptive ranges (MRRs) (Mori et al., 1992). We used intracellular recording and staining to study the chemosensory tuning of single PNs with arborizations restricted to glomerulus 35 (G35), which can be identified readily in both sexes (Rospars and Hildebrand, 1992, 2000). As stimuli, we used a set of diverse, behaviorally relevant volatiles that are released by host plants of Manduca (Loughrin et al., 1990; Fraser et al., 2003; Raguso et al., 2003).

\section{Materials and Methods}

Preparation. Manduca sexta (L.) (Lepidoptera: Sphingidae), reared in the laboratory on an artificial diet, were used 1-3 d after adult emergence. Animals were dissected and prepared for intracellular recording according to established procedures (King et al., 2000). After mechanical removal of the perineural sheath covering the $\mathrm{AL}$, the preparation was continuously superfused with physiological saline solution containing the following (in $\mathrm{mm}$ ): $150 \mathrm{NaCl}, 3 \mathrm{CaCl}_{2}, 3 \mathrm{KCl}, 10 \mathrm{~N}$-[Tris(hydroxymethyl)methyl]-2-aminoethanesulfonic acid buffer, $\mathrm{pH}$ 6.9, and 25 sucrose (Christensen and Hildebrand, 1987).

Stimulation. The stimulation procedure has been described previously (Reisenman et al., 2004). Briefly, the cut end of one antenna was inserted into a glass capillary tube filled with physiological saline solution, which served both as a holder to position the antenna and as an electrode for monitoring antennal responses to olfactory stimulation. An L-shaped glass tube delivered a constant flow of humidified, charcoal-filtered air to the antenna (1.9 L/min). Odor compounds were injected ( $2 \mathrm{ml} ; 200 \mathrm{~ms}$ ) into the constant air stream (and thus diluted by $\sim 1: 4$ ) via a computerdriven syringe olfactometer (Selchow, 1998). The tip of a stimulus syringe mounted in the olfactometer was inserted into a small hole in the side of the glass tube. A funnel connected to a negative-pressure line was positioned near and behind the preparation to remove stimulus volatiles after delivery to the antenna.

The odor compounds used in this study (Fig. 1) were as follows: ocimene (3,7-dimethyl-1,3,6-octatriene; catalog \#74730; 95\% pure; mixture of isomers) from Fluka (Buchs, Switzerland); benzyl alcohol (catalog \#30519-7; 99.8\% pure), cis-3-hexenyl butyrate (catalog \#W340200; $>98 \%$ ), geraniol (trans-3,7-dimethyl-2,6-octadien-1-ol; catalog \#G-5135; 98\%), hexan-1-ol (catalog \#47142; 99\%; hereinafter referred to as hexanol), ( \pm )linalool [( \pm )3,7-dimethyl-1,6-octadien-3-ol; catalog \#L2602; 97\% pure], methyl salicylate (methyl 2-hydroxybenzoate; cata$\log \# 240826$; >99\%), nerol (cis-3,7-dimethyl-2,6-octadien-1-ol; catalog \#26890-9; 97\%), nonanal (catalog \#76310; >95\%), phenylacetaldehyde (catalog \#P0145; 95\% pure), trans-2-hexenal (catalog \#132659; 98\% pure) from Sigma-Aldrich (St. Louis, MO); and cis-3-hexenyl acetate (c3HA) (catalog \#H2137; >97\%), cis-3-hexenyl propionate (catalog \#P858; >97\%), and cis-3-hexenyl benzoate (catalog \#B1039; >98\%) from Tokyo Chemical Industries (Tokyo, Japan). These compounds are found among the volatiles emitted by host plants of Manduca (Loughrin et al., 1990; Fraser et al., 2003; Raguso et al., 2003) and have been shown to evoke responses from the antenna (Fraser et al., 2003) (C. E. Reisenman, unpublished observations) and/or from olfactory receptor cells (ORCs) in trichoid type-A antennal sensilla in females (Shields and Hildebrand, 2001).

Single odor compounds were diluted in odorless mineral oil (SigmaAldrich) and prepared as described previously (Reisenman et al., 2004). Dilutions ranged from $10^{-6}$ to $10^{-2}(\mathrm{v} / \mathrm{v})$. Fifty microliters of solution were applied to a disk of filter paper and inserted into a $20 \mathrm{ml}$ stimulus syringe; control syringes contained $50 \mu \mathrm{l}$ of mineral oil alone. At a concentration of $10^{-3}$, the load of odor compound on the filter paper ranged from $40 \mu \mathrm{g}$ for hexanol to $52 \mu \mathrm{g}$ for benzyl alcohol.

Intracellular recording and staining. Sharp microelectrodes were made from borosilicate glass capillaries with filament $(1 \mathrm{~mm}$ outer diameter; 0.58 or $0.75 \mathrm{~mm}$ inner diameter; Sutter Instruments, Novato, CA) on a laser puller (P-2000; Sutter Instruments). The tip of the micropipette was

\section{Aliphatics}<smiles>CC/C=C\CCOC(C)=O</smiles>

(1)

cis-3-hexenyl acetate<smiles>CC/C=C\CCOC(=O)CC</smiles>

(2)

cis-3-hexenyl propionate<smiles>CC/C=C\CCOC(=O)CCC</smiles><smiles>[131I-]</smiles>

cis-3-hexenyl butyrate

\section{Monoterpenoids}

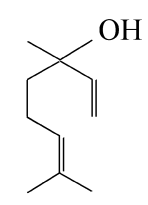

(8) linalool<smiles>C=CC(C)=CCC=C(C)C</smiles><smiles>c1ccccc1</smiles>

ocimene<smiles>CC/C=C\CCO</smiles>

(4) cis-3-hexen-1-ol

$\mathrm{OH}$<smiles>CCCCCCCCCCCC</smiles><smiles>CCC/C=C/C=O</smiles><smiles>c1ccccc1</smiles>

trans-2-hexenal<smiles>CCCCCCCCC=O</smiles><smiles></smiles>

nonanal

\section{Aromatics}<smiles>OCc1ccccc1</smiles>

(11)

benzyl

alcohol<smiles>COC(=O)c1ccccc1O</smiles>

(12)

methyl salicylate<smiles>CCC=CCCOC(=O)c1ccccc1</smiles>

cis-3-hexenyl benzoate<smiles>O=CCc1ccccc1</smiles>

phenyl acetaldehyde
Figure 1. Chemical structures of some of the odor compounds used in this study. All are emitted by host plants of Manduca. Compounds are numbered in the order shown in Figure 6.

filled with a $65 \mathrm{~mm}$ solution of Lucifer yellow CH (Sigma-Aldrich) in 200 $\mathrm{mm} \mathrm{LiCl}$, or with a solution of Alexa Fluor 568 hydrazide (10 mM in 200 mм KCl; Invitrogen, San Diego, CA), and the shaft, with $2 \mathrm{~m} \mathrm{LiCl} \mathrm{(elec-}$ trode resistances ranged from 100 to $350 \mathrm{M} \Omega$ ). Microelectrodes were manipulated to penetrate the glomerular region of the AL above the known location of G35 and/or the LFGs, so that G35-PNs, latLFG-PNs, or other PNs in neighboring glomeruli could be targeted in these exper- 

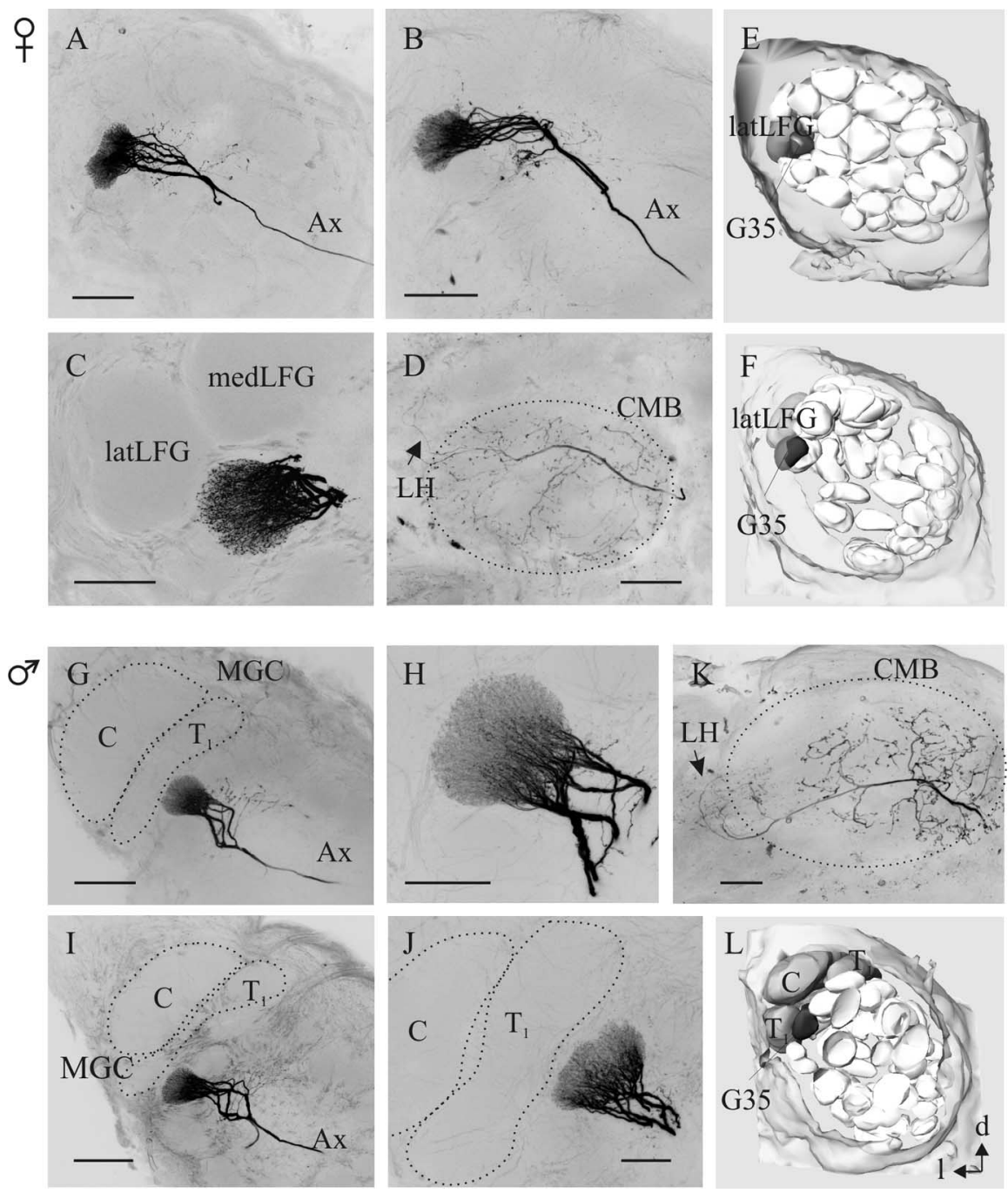

Figure 2. Examples of PNs from females $(\boldsymbol{A}-\boldsymbol{F})$ and males $(\boldsymbol{G}-\boldsymbol{L})$ with dendritic arborizations confined to $\mathrm{G} 35$ [described by Rospars and Hildebrand (1992, 2000)]. A-D, G-K, Confocal stacks collected from whole-mount preparations or after embedding in plastic and sectioning. In both sexes, G35-PNs have their somata in the anterior group of AL neuronal cell bodies (not visible in these figures; see Results) and an axon (Ax) projecting from the AL. $\boldsymbol{C}, \boldsymbol{H}, \boldsymbol{J}$, Higher-magnification images of female ( $\boldsymbol{C}$ and male $(\boldsymbol{H}, \boldsymbol{J})$ G35-PNs after sectioning ( $\boldsymbol{C}$ and $\boldsymbol{H}$ are from the PNs shown in $A$ and $\mathbf{G}$, respectively). These figures illustrate the fine and dense dendritic arborizations of G35-PNs and the close anatomical relationship between G35 and the LFGs (latLFG and medLFG are the lateral and medial LFGs, respectively) in females ( $C$ or the MGC ( $C$ and $\mathrm{T}_{1}$ are the principal glomeruli of the MGC, Cumulus and Toroid 1, respectively) in males $(\boldsymbol{H}, \boldsymbol{J}) . \boldsymbol{D}, \boldsymbol{K}$, Axonal projections of the PNs shown in $\boldsymbol{B}$ (female) and $\boldsymbol{G}$ (male), showing collaterals in the calyces of the ipsilateral mushroom body (CMB) (dotted lines) and terminals in the lateral horn (LH) of the protocerebrum (arrows). Note that the morphological features and projection sites in the protocerebrum of G35-PNs are indistinguishable in males and females. $\boldsymbol{E}_{\text {, }}$ $\boldsymbol{F}, \boldsymbol{L}, 3 \mathrm{D}$ reconstructions (frontal view) of ALs from three brains with physiologically and morphologically characterized PNs from females $(\boldsymbol{E}, \boldsymbol{F})$ and from a male $(\boldsymbol{L})$. These reconstructions show that, in both sexes, $\mathrm{G} 35$ (which houses the dendritic arborizations of the stained PNs, in black) occupies the same relative position with respect to the other glomeruli of the AL. The latLFG $(\boldsymbol{E}, \boldsymbol{F})$ (the medLFG is not visible in this view) and the $T_{1}$ and $C(\boldsymbol{L})$ are shown in gray. One, three, and two anterior glomeruliare omitted $(\boldsymbol{E}, \boldsymbol{F}$, and $\boldsymbol{L}$, respectively) for visualization of G35. d, Dorsal; I, lateral. Scale bars: $A, B, D, G, I, K, 100 \mu \mathrm{m} ; C, H, J, 50 \mu \mathrm{m}$.

iments. The responses of an impaled neuron to stimulation of the ipsilateral antenna were amplified 10-fold and digitized at $20 \mathrm{kHz}$ (Axoclamp-2A; Digidata 1200 series Interface; Molecular Devices, Foster City, $\mathrm{CA}$ ). Data were analyzed with custom-made programs written in Matlab (The Mathworks, Natick, MA).

After physiological characterization, neurons were injected with either Lucifer yellow or Alexa 568 (see above) by passing hyperpolarizing current $(0.2-1 \mathrm{nA})$ for $6-40 \mathrm{~min}$. The duration of intracellular impalements, including both recording and dye injection, was variable (average, $20 \mathrm{~min}$; maximum, 40-50 min). On completion of an experiment, the brain was excised and immersed in $2.5 \%$ formaldehyde fixative solution, $\mathrm{pH} 7.2$, for at least $3 \mathrm{~h}$, dehydrated through a graded series of ethanol solutions, and cleared with methyl salicylate (Sigma-Aldrich). Cleared brains were imaged as whole mounts (optical sections, $2 \mu \mathrm{m}$ thick) with a laser-scanning confocal microscope (Nikon, Tokyo, Japan; PCM 2000 , equipped with a $457 \mathrm{~nm}$ argon laser and a $546 \mathrm{~nm}$ green $\mathrm{HeNe}$ laser). Brains were returned to $100 \%$ ethanol and embedded in Spurr's resin (Electron Microscopy Sciences, Ft. Washington, PA) for sectioning at $48 \mu \mathrm{m}$.

For three-dimensional (3D) reconstructions, brains with intracellularly stained cells were rehydrated, immersed overnight in $4 \%$ glutaraldehyde fixative solution, $\mathrm{pH} 7.3$, dehydrated, cleared, and imaged as whole mounts (optical sections, $0.6 \mu \mathrm{m}$ thick) as described above. The borders of the AL, the LFGs (in females) or the MGC (in males), the glomerulus receiving arborizations of the neuron of interest, and the rest of the glomeruli were reconstructed using Amira software (Konrad-Zuse-Zentrum für Informationstechnik, Berlin, Germany).

Statistical analysis. Differences between two means were compared by means of the Wilcoxon matched-pairs test (for paired samples) or the Mann-Whitney $U$ test (for independent samples). Differences between three or more paired means were compared using Friedman ANOVAs; significant results $(p<0.05)$ were followed by modified nonparametric Tukey's tests for repeated measures (Zar, 1999). Although some figures show normalized data, in all cases statistics were applied to absolute values. Comparisons involving sample sizes smaller than five were not analyzed statistically.

\section{Results}

Results were obtained from 30 morphologically characterized uniglomerular PNs, each from a different animal (25 PNs from as many females and $5 \mathrm{PNs}$ from as many males). Of the female PNs, 10 had arborizations restricted to G35, an identified glomerulus described previously (Rospars and Hildebrand, 1992, 2000) (these neurons are referred to as G35-PNs), 7 in the latLFG (latLFG-PNs), and 8 in glomeruli different from but neighboring the LFGs and G35. All impaled male PNs were G35-PNs. Three G35-PNs were characterized only morphologically (i.e., odor compounds were not tested). Not all odor compounds and/or concentrations were tested in all PNs. Eight other neurons (four from females and four from males) could not be identified morphologically with certainty, but we suspect that they were G35-PNs (responses from five of these neurons were quantified and included in Figs. $4 E, F, 5 B$, and 7).

\section{Morphological characterization of G35-PNs}

Figure 2 shows examples of PNs from females (Fig. $2 A-D$ ) and males (Fig. $2 G-K$ ) with arborizations restricted to G35. The somata of G35-PNs were not always intact after tissue processing, but it was possible nevertheless in all preparations to follow the main neurite of each PN to confirm its origin in the anterior group of AL neuronal cell bodies (this group has only $16 \pm 2$ cell 
bodies in both sexes) (Homberg et al., 1988). We found that the morphological features of G35-PNs were nearly identical in females and males. In both sexes, the primary neurites of G35-PNs gave rise to an extensive network of very fine branches that arborized densely in the glomerulus (Fig. 2C, H,J). The axons of G35-PNs projected through the inner-antenocerebral tract to the calyces of the ipsilateral mushroom body and the lateral horn of the protocerebrum (Fig. 2D,K). Figure 2, E, F, and $L$, are examples of $3 \mathrm{D}$ reconstructions of ALs obtained from female and male brains, respectively, with physiologically characterized, intracellularly stained neurons. These reconstructions allowed us to confirm across animals the identity of the glomerulus housing the dendritic arborizations of the stained PNs and to show that in both sexes G35 occupies the same relative position in the glomerular array. In females, G35 is adjacent to the sexually dimorphic latLFG (Fig. 2C,E,F), whereas in males, G35 is adjacent to the malespecific toroid 1 , one of the glomeruli of the MGC (Fig. $2 J, L$ ).

\section{Responses of G35-PNs to cis-3-hexenyl acetate}

We identified a total of 15 G35-PNs in both sexes and tested 12 of them ( 8 from as many females and 4 from as many males) with several odor compounds. In all cases, we found that, of the compounds tested, these PNs responded most strongly to antennal stimulation with $\mathrm{c} 3 \mathrm{HA}$. Figure 3 shows examples of electrophysiological recordings obtained from G35-PNs in a female (Fig. $3 A$ ) and a male (Fig. $3 B$ ) to antennal stimulation with $\mathrm{c} 3 \mathrm{HA}$ and other odor compounds. In both sexes, responses to 3 HA consisted of an initial rapid membrane hyperpolarization (black arrows) followed by a strong depolarization with spiking and a delayed hyperpolarizing phase during which all spiking was suppressed (open arrows). The rate of spiking during the excitatory phase increased with increasing c3HA concentrations (Figs. $3 A$, top traces; 4). In females, the chemically related aliphatic odor compound trans-2-hexenal evoked a qualitatively similar triphasic response, but the excitatory phase of the response was less intense even with elevated concentrations (Fig. 3A, bottom trace, middle). For instance, at a dilution of $10^{-3}, \mathrm{c} 3 \mathrm{HA}$ and trans-2-hexenal evoked $57 \pm 21$ and $16 \pm 5$ spikes, respectively (means $\pm \mathrm{SE} ; n=4$ female PNs). All male G35-PNs tested with trans-2-hexenal, tested with the $10^{-2}$ dilution $(n=2)$, failed to respond to it.

All G35-PNs responded strongly to c3HA, but some exhibited brief response bursts that were time-locked to the stimulus pulse, whereas others exhibited prolonged response patterns with intermittent bursts of spikes interrupted by silent periods (data not shown). At a dilution of $10^{-4}$, the net number of spikes (responses to the control were subtracted) evoked by c3HA stimulation was $27 \pm 11$ (mean $\pm \mathrm{SE} ; n=7 \mathrm{PNs}$; median, 16; range, $10-90)$ in females and $17 \pm 1.8$ (mean \pm SE; $n=4$ PNs; median,
17; range, 8.7-22) in males. In this same group of PNs, the odorevoked peak instantaneous spike frequency (ISF) was $157 \pm 18$ $\mathrm{Hz}$ (median, $153 \mathrm{~Hz}$; range, 75-208 Hz) in females and $104 \pm 13$ $\mathrm{Hz}$ (median, $105 \mathrm{~Hz}$; range, 29-118 Hz) in males.

We measured the dose-dependent effects on different response parameters in identified G35-PNs in both females (Fig. $4 A-D$, open symbols) and males (Fig. $4 A-D$, closed symbols) that were tested with at least three concentrations (including the highest one, $10^{-3}$ ). We found that increasing c3HA concentrations evoked a greater net number of spikes, a higher peak ISF, a longer-lasting excitation, and a shorter delay (the inverse of the delay is shown in the figure) to the onset of the excitatory response phase (Fig. 5A-D). At the highest concentration, the net number of spikes and the duration of the excitation showed a high variability (Fig. $4 C$ ), which is attributable to the unusually prolonged excitation observed in some of the PNs tested at that concentration.

In females, the threshold concentration for responses of G35-PN to c3HA (better visualized in Fig. 4 B, open symbols) was below the $10^{-6}$ dilution (our stimulus delivery system further diluted stimulus compounds fourfold). After correcting for control responses, the net number of spikes, duration of response, and peak ISF evoked by stimulation with this dosage of $\mathrm{c} 3 \mathrm{HA}$ 

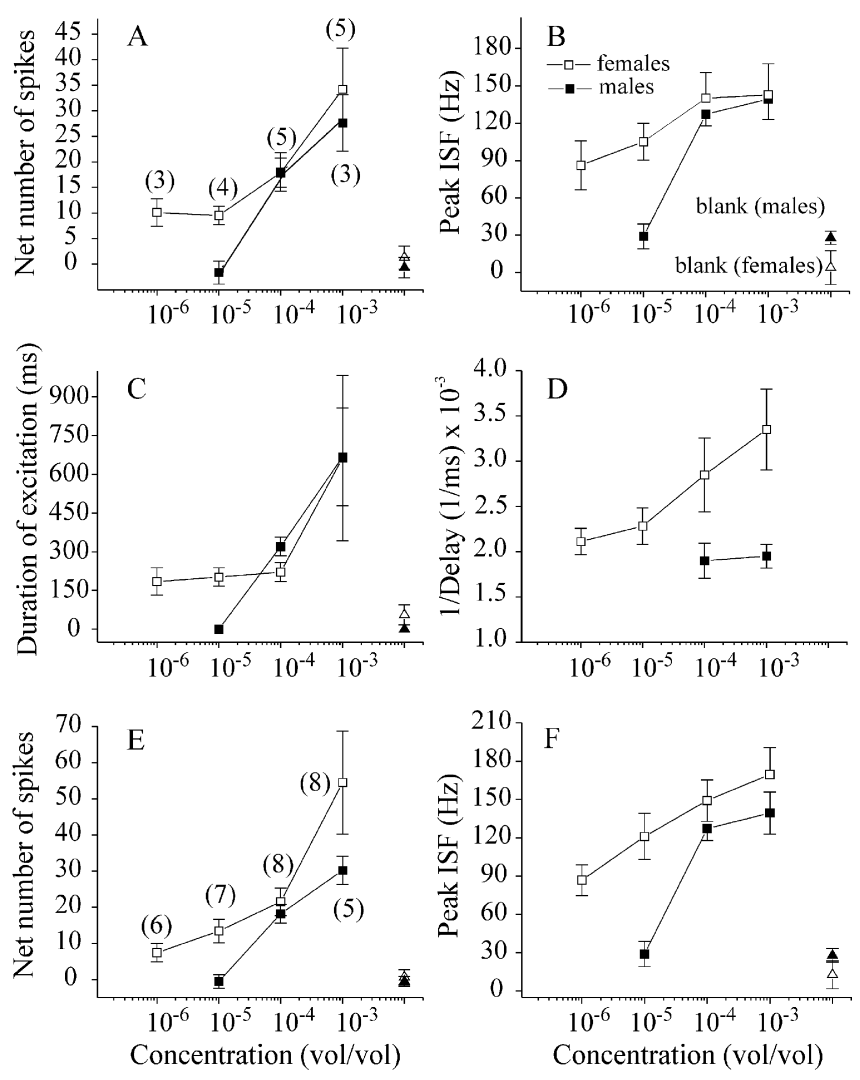

Figure 4. Dose-response profiles of G35-PNs based on four physiological parameters of the response (mean $\pm \mathrm{SE}$ ) as a function of the concentration of $\mathrm{c} 3 \mathrm{HA}$ (log scale). $\boldsymbol{A}-\boldsymbol{D}$, Five G35-PNs from as many females (open symbols) and three G35-PNs from as many males (closed symbols) were tested with several concentrations of $\mathrm{c} 3 \mathrm{HA}$ (squares) and the mineral oil blank (triangles). Female PNs were tested with at least three concentrations: $10^{-3}, 10^{-4}$, and one or two of the lowest concentrations $\left(10^{-6}\right.$ and/or $\left.10^{-5}\right)$. All male PNs were tested with the three highest concentrations. The number of PNs tested at each concentration is indicated in $\boldsymbol{A}$. $\boldsymbol{A}$, The net number of spikes during the excitatory phase of the response (the mean number of spikes during the prestimulation period was subtracted). $\boldsymbol{B}$, The peak ISF measured during the excitatory phase of the response. $\boldsymbol{C}$, The duration of the excitatory response (time elapsed between the first and the last spike evoked by the stimulus). $\boldsymbol{D}$, The inverse of the delay, calculated as the inverse of the time elapsed between the activation of the device controlling the stimulus delivery system and the first spike evoked by the odor stimulation. In both sexes, and for all of the physiological parameters measured, the response of $\mathrm{G} 35$-PNs to $3 \mathrm{HA}$ increased with increasing concentration. Note that the sensitivity threshold of female PNs $\left(<10^{-6} \mathrm{v} / \mathrm{v}\right.$, better visualized in $\boldsymbol{B}$ ) is lower than that of male PNs. $\boldsymbol{E}, \boldsymbol{F}$, Same as $\boldsymbol{A}$ and $\boldsymbol{B}$, but including additional data from five PNs ( 3 from females and 2 from males) tentatively identified as G35-PNs. The number of PNs tested at each concentration is indicated in $\boldsymbol{E}$. Error bars indicate $\mathrm{SE}$.

were as follows: mean $\pm \mathrm{SE}(n=4 \mathrm{PNs}), 10.3 \pm 1.9$ spikes, $152 \pm$ $10 \mathrm{~ms}$, and $76 \pm 22 \mathrm{~Hz}$, respectively. In contrast, none of the male G35-PNs tested responded to this or the $10^{-5}$ dilution (Fig. $4 A-D$, closed symbols). At the $10^{-5}$ dilution, c3HA evoked a response statistically different from the blank in females (Wilcoxon matched-pairs test; $Z=2.02 ; n=5 ; p<0.05$ ) and, furthermore, different from responses of male G35-PNs (MannWhitney $U$ tests for both the net number of spikes and the peak ISF; $\left.Z=-2.4 ; n_{1}=4 ; n_{2}=5 ; p<0.05\right)$. Additional data obtained from five other neurons tentatively identified as G35-PNs confirmed these results (Fig. $4 E, F$ ).

These results show that both male and female G35-PNs responded in a dose-dependent manner to c3HA, but female PNs had a response threshold at least one to two orders of magnitude lower than that of male G35-PNs.
Odor preference of G35-PNs for cis-3-hexenyl acetate

Figure $5 A$ shows electrophysiological recordings obtained from G35-PNs in a female (left traces) and a male (right traces) in response to antennal stimulation with $\mathrm{c} 3 \mathrm{HA}$ and its structural homologs cis-3-hexenyl propionate (c3HP) and cis-3-hexenyl butyrate (c3HB). In both cases, $\mathrm{c} 3 \mathrm{HA}$ evoked the strongest responses at both the $10^{-3}$ and $10^{-4}$ dilutions. In contrast, the highest concentration of $\mathrm{c} 3 \mathrm{HB}$ evoked only a few spikes (in the female $\mathrm{PN}$ ) or no response (in the male PN). The highest concentration of c3HP also evoked a response, but weaker (and more delayed) than that evoked by c3HA, whereas the lowest evoked little response in both sexes. This marked preference of G35-PNs for the acetate was observed across individuals. Figure $5 B$ shows the net number of spikes evoked by stimulation with c3HA and c3HP in G35-PNs from females (white bars) and males (hatched bars). In both sexes, c3HA evoked the highest response [an analysis of the peak ISF yielded the same result (data not shown)]. In all $\mathrm{PNs}$ in which $\mathrm{c} 3 \mathrm{HB}$ was tested, it evoked the weakest responses. The same odor preference $(\mathrm{c} 3 \mathrm{HA}>\mathrm{c} 3 \mathrm{HP} \gg \mathrm{c} 3 \mathrm{HB})$ was observed in two additional female neurons that were tentatively identified as G35-PNs.

Figure $5 C$ shows the effect of the concentration of the stimulus compound on the responsiveness of G35-PNs from a female (top panel) and from a male (bottom panel) tested with seven different host plant volatiles. Once again, the strongest responses in both PNs were evoked by c3HA, followed by c3HP, and the female PN showed a lower sensitivity threshold to $3 \mathrm{HA}$ than the male PN. The remaining odor compounds, even when tested at high concentrations, evoked weak or no responses. Another female G35-PN and four other male neurons (one G35-PN and three neurons tentatively identified as G35-PNs) showed the same odor preference. Thus, although female PNs were more sensitive to $\mathrm{c} 3 \mathrm{HA}$ than male PNs, they had similar breadth of tuning (at least for the compounds tested in both sexes, c3HA, c3HP, c3HB, benzyl-alcohol, ( \pm )linalool, trans-2-hexenal, and methyl-salicylate).

We then challenged two additional G35-PNs (in two females) with a wider panel of odor compounds at a dilution of either $10^{-3}$ or $10^{-4}$ (Fig. 6, gray and white bars, respectively). Again, c3HA evoked the strongest responses as measured by the net number of spikes (Fig. 6A), peak ISF (Fig. 6B), duration of the excitatory response (Fig. 6C), and response delay (Fig. 6D) (the inverse of the delay is shown). At the highest concentration $\left(10^{-3}\right.$ dilution), benzyl alcohol evoked a high peak ISF (Fig. $6 \mathrm{~B}$, arrowhead), but c3HA evoked the greatest response as measured by all other response parameters (Fig. 6A, C,D, arrows). This figure also shows that the specificity of G35-PNs was higher at the lowest concentration. For instance, at a dilution of $10^{-4}$, only small increases in spiking resulted from stimulation with other odor compounds (Fig. 6A, white bars), including those that evoked moderate rates of spiking at the highest concentration (Fig. 6A, asterisks). This figure also shows that the number of spikes and the duration of the evoked excitation (Fig. 6A, C) are better descriptors of the odor selectivity than, for instance, the response delay (Fig. 6D).

Overall, these results show that, among the panel of odor compounds tested, both female and male G35-PNs are more sensitive and preferentially responsive to $\mathrm{c} 3 \mathrm{HA}$.

\section{Inhibitory interactions between G35 and other glomeruli in the female}

In contrast to the strong excitatory response to c3HA that we observed in G35-PNs, stimulation with ( \pm )linalool evoked a pronounced inhibitory response in females (Fig. $3 A$, middle row, 
arrowheads) but not in males (Fig. 3B, middle panel). Membrane hyperpolarization was observed in six of eight morphologically characterized G35-PNs (in females) that were tested with $( \pm)$ linalool and in three putative G35-PNs (i.e., neurons that were not characterized morphologically with certainty). This odor compound selectively activates PNs innervating the neighboring latLFG (King et al., 2000) but also evokes responses in PNs in other neighboring glomeruli (Reisenman et al., 2004). None of the seven male neurons tested (four identified G35PNs and three putative G35-PNs) (Fig. 3B) showed inhibitory responses to $( \pm)$ linalool (even when tested at the $10^{-2}$ dilution), presumably because males have no latLFG.

In contrast to the $( \pm)$ linalool-evoked hyperpolarization observed in female G35-PNs, stimulation with c3HA evoked in both sexes a fast hyperpolarization followed by a strong excitatory phase with spiking (Fig. 3, first row, black arrows). Such fast hyperpolarization was observed in all tested G35-PNs $(n=12)$ and in all of the eight putative G35-PNs. In both sexes, the rate of spiking during the excitatory phase of the response increased with increasing concentration of c3HA (Fig. 4), but we did not observe this dosedependent effect ( $n=4$ female G35-PNs) when $( \pm$ )linalool was used as the stimulus (the postinhibitory spiking is most likely a rebound effect) (Fig. 3A).

As shown in Figure 7, the characteristics of the hyperpolarization evoked by these two odor compounds were also quantitatively different. The early hyperpolarization evoked by ( \pm )linalool was slower (slope of the hyperpolarization; white bars), reached a greater amplitude (light gray bars), and was more prolonged (dark gray bars) than that evoked by c3HA. The delay to the onset of the hyperpolarization (hatched bars), in contrast, was shorter when the PNs were stimulated with c3HA. Similar differences were also observed in other G35-PNs that were not included in the figure (because different concentrations of the two compounds were used). These differences suggest that the early hyperpolarizing responses evoked by c3HA and $( \pm)$ linalool might be mediated by different inhibitory synaptic mechanisms.

\section{Responses to cis-3-hexenyl acetate in PNs in glomeruli neighboring G35 in the female}

Having shown that G35-PNs were preferentially responsive to c3HA, we then tested in females whether PNs arborizing in neighboring glomeruli could also respond to $33 \mathrm{HA}$. Figure $8 \mathrm{~A}$ shows an example of a $\mathrm{PN}$ from a female with arborizations restricted to the latLFG, which is adjacent to G35. As we showed previously (Reisenman et al., 2004), (+)linalool evoked a strong excitatory response in these PNs (Fig. $8 E$, hatched bars) (Friedman ANOVA followed by post hoc comparisons; $p<0.05 ; n=7 \mathrm{PNs}$ ). ( \pm )Linalool also evoked excitatory responses from latLFG-PNs (King et al., 2000), although less strongly than (+)linalool (Reisenman, unpublished observations). In contrast, stimulation with the $10^{-2}$ dilution of c3HA (which is at least three orders of magnitude above the sensitivity threshold of G35-PNs) did not evoke a response different from that to the blank ( post hoc comparison; $p>0.05 ; n=7$ PNs) (Fig. $8 E$, gray bar).

We also studied responses (in females) of PNs with arborizations in other glomeruli near G35 and the LFGs but not individually mapped to the atlas of AL glomeruli. A total of eight such PNs are included in this study (Fig. $8 B-D$ shows three examples), five had their cell bodies in the lateral group of neuronal somata and three in the medial group. All of these PNs had dendritic arborizations that were distinctly different from the fine and dense arborizations of G35-PNs (compare with Fig. 2). As a group, these PNs gave little response to stimulation with c3HA (Fig. $8 F$ ), and their responses to c3HA were statistically different from the responses of G35-PNs (Mann-Whitney $U$ test; $Z=$ $2.84 ; p<0.005 ; n_{1}=6$ G35-PNs; $n_{2}=8$ non-G-35 PNs).

\section{Discussion}

To test the principle of odor selectivity in single PNs, we took advantage of the possibility of identifying individual glomeruli in 
A

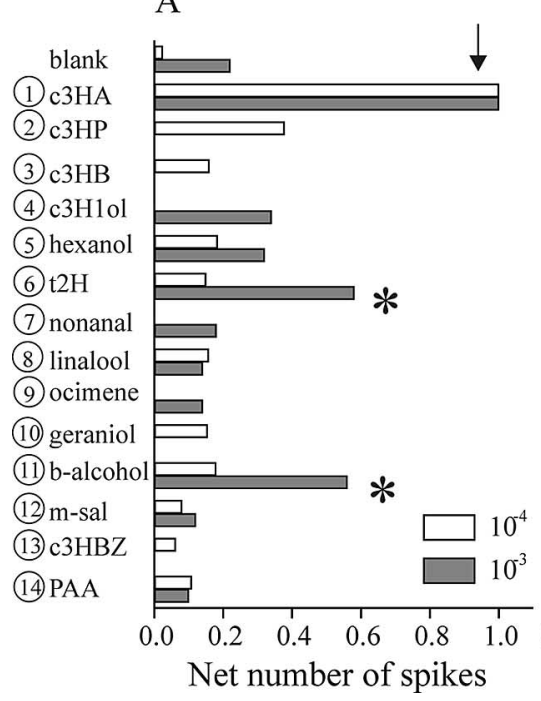

B

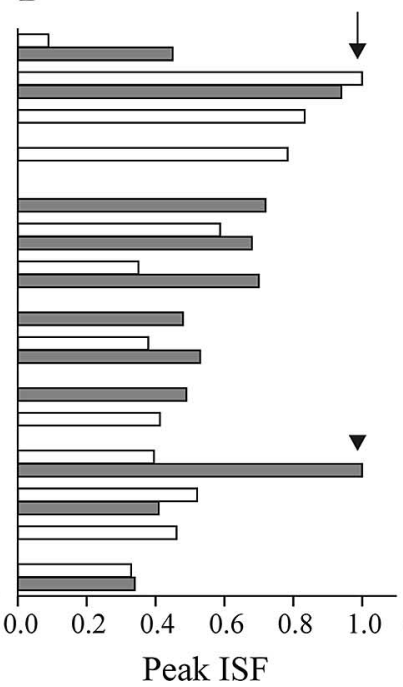

C

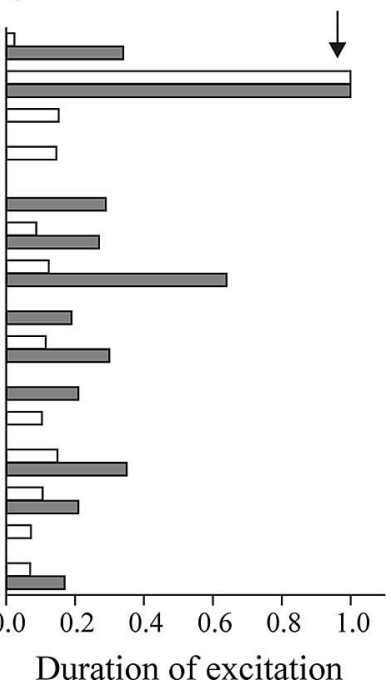

$\mathrm{D}$

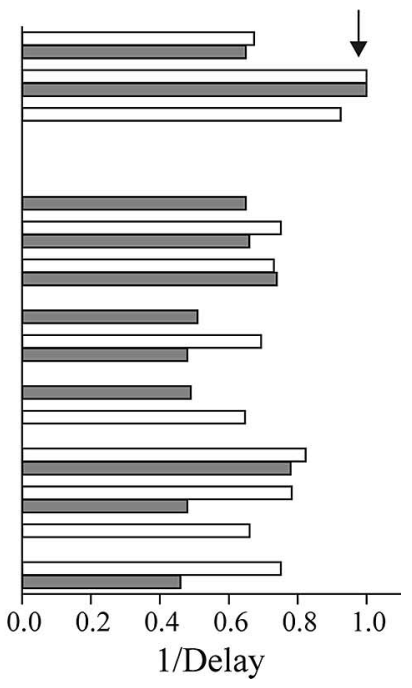

Figure 6. Odor preferences of female G35-PNs. Two G35-PNs were tested with several odor compounds (listed at the left) at a single concentration (1 PN tested with $10{ }^{-3}$, gray bars; 1 PN tested with $10^{-4}$, white bars) and the mineral-oil blank (gray and white bars for the PNs tested with $10^{-3}$ and $10^{-4}$, respectively). Circled numbers refer to the odor compounds shown in Figure $1 . \boldsymbol{A}$, Net number of spikes. $\boldsymbol{B}$, Peak ISF. C, Duration of the excitatory response. $\boldsymbol{D}$, Inverse of the delay to the onset of the excitatory response. For each PN and response parameter, responses were normalized to the maximum. At both concentrations, and for all of the parameters quantified, c3HA evoked the strongest responses (arrows). Note that some parameters of the response (e.g., number of spikes and duration, $\boldsymbol{A}$ and $\boldsymbol{C}$, respectively) are better descriptors of the odor tuning, particularly at the lowest concentration; the inverse of the delay (D), although it was the largest for $\mathbf{C} 3 \mathrm{H} A$, was not much different from that observed by stimulation with other compounds. At the highest concentration, but not at the lowest, other odor compounds could evoke moderate spiking activity ( $\boldsymbol{A}$, asterisks). At the highest concentration benzyl alcohol (b-alcohol; $\boldsymbol{B}$, arrowhead) evoked a slightly higher peak ISF than c $3 \mathrm{HA}$. The morphology of the PN tested with the highest concentration (gray bars) is illustrated in Figure 2, A and C. Some of the odor compounds were tested in only one of the two PNs. c3H1ol, cis-3-Hexen-1-ol; t2H, trans-2-hexenal; b-alcohol, benzyl alcohol; m-sal, methyl salicylate; c3HBZ, cis-3-hexenyl benzoate; PAA, phenyl acetaldehyde.

the AL of Manduca. We found that, in both sexes, PNs innervating one of these glomeruli, G35, are morphologically equivalent and preferentially responsive to low concentrations of the plant volatile c3HA. Although a small number of odor compounds were tested, our results suggest that the MRR of this glomerulus in the main olfactory pathway of Manduca is centered on a few structurally related compounds.

Imaging studies using various activity markers have shown that odor compounds evoke spatially organized, combinatorial patterns of neural activity in OBs (Mombaerts et al., 1996; Friedrich and Korsching, 1998; Johnson et al., 1998; Rubin and Katz, 1999; Belluscio and Katz, 2001; Xu et al., 2003; Takahashi et al., 2004) and ALs (Joerges et al., 1997; Carlsson et al., 2002; Hansson et al., 2003). In most of these cases, however, the cell types imaged were unknown, although in others (Zhao et al., 1998; Araneda et al., 2000; Ma and Shepherd, 2000; Gaillard et al., 2002; Wachowiak and Cohen, 2003) primary-afferent input was imaged. Imaging studies in fruit flies, Drosophila melanogaster (Ng et al., 2002; Wang et al., 2003; Suh et al., 2004), and in honeybees, Apis mellifera (Sachse and Galizia, 2002), however, have examined the specific contribution of PNs to these activity patterns, and the present study in Manduca is based on electrophysiological recordings from PNs.

In many insect species, it is well established that certain PNs are narrowly tuned to sex-pheromone components (Hansson et al., 1991; Vickers et al., 1998; Kanzaki et al., 2003), but PNs of glomeruli not involved in processing of pheromonal information are generally considered to be "broadly tuned" (Perez-Orive et al., 2002; Davis, 2004; Wilson et al., 2004). In Manduca, however, we obtained evidence from an identified glomerulus (the LPOG) supporting the hypothesis that $\mathrm{PNs}$ processing information about food-related volatiles $\left(\mathrm{CO}_{2}\right.$ in the case of the LPOG-PNs) (Guerenstein et al., 2004a,b) can also have high specificity (Gue- renstein et al., 2004b) (in both sexes, the LPOG receives primaryafferent input from a sensory organ containing only $\mathrm{CO}_{2}-$ responsive ORCs). The present study provides another example supporting this hypothesis, because we found that G35-PNs are preferentially responsive to an odor compound emitted by plants, including host plants of Manduca (Raguso et al., 2003). Furthermore, their morphological and odor-response features were remarkably conserved across individuals and sexes (Figs. 2-5).

Two studies, one using the moth Spodoptera littoralis (Sadek et al., 2002) and the other using D. melanogaster (Wilson et al., 2004), found that PNs in identified glomeruli with no apparent sexual dimorphism responded to many odor compounds, and it was therefore concluded that the PNs were broadly tuned. Importantly, however, neither of these studies measured the doseresponse characteristics of the neurons. Recently, Masante-Roca et al. (2005), based on findings in two animals, reported that PNs thought to arborize in the same glomerulus responded to different odor stimuli. Here, we found that G35-PNs could respond to other stimuli in addition to $\mathrm{c} 3 \mathrm{HA}$ at high concentrations, but their specificity was higher at lower stimulus concentrations (Figs. 5, 6). In comparison with latLFG-PNs, however, some G35-PNs had low signal-to-noise ratios (compare Figs. 6, 8E). Other authors found high specificity in pheromone-processing AL neurons (Anton et al., 1997; Hartlieb et al., 1997; de Bruyne et al., 2001) or ORCs responsive to plant volatiles (Hansson et al., 1999; Røstelien et al., 2000; Angioy et al., 2003) only at low, natural stimulus intensities. These findings, together with ours, illustrate the importance of testing odor stimuli over a range of concentrations to characterize the MRRs of olfactory neurons.

We also tested (in females) whether glomeruli situated near G35 were responsive to $\mathrm{c} 3 \mathrm{HA}$. As a group, PNs arborizing in several neighboring glomeruli did not respond (or responded 


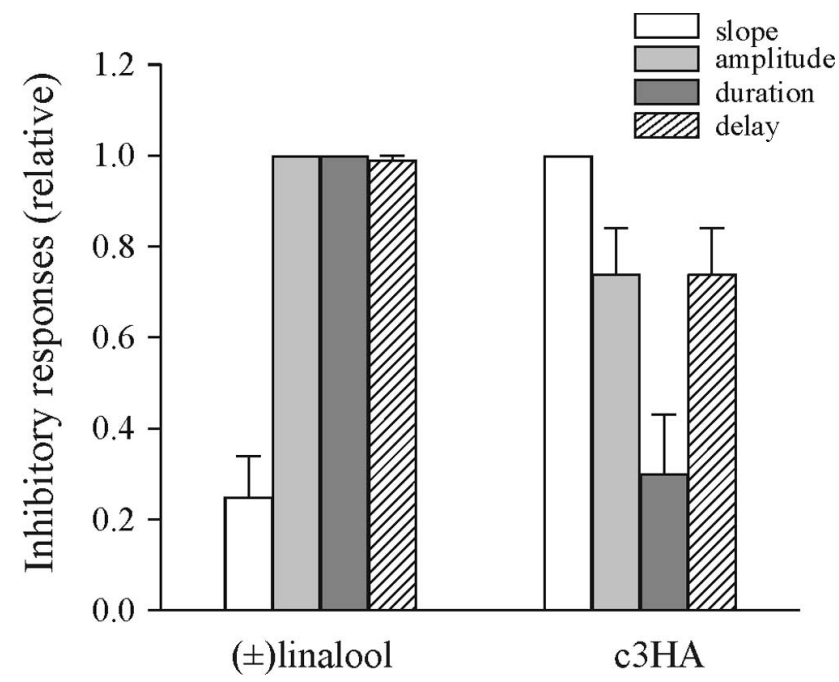

Figure 7. Quantitative analysis of the early hyperpolarizations evoked by c3HA and ( \pm )linalool in female G35-PNs. These odor stimuli were tested at dilutions of $10^{-3}(\mathrm{v} / \mathrm{v})$. Data (relative values) represent means $\pm \mathrm{SE}(n=4)$ of the slope of the stimulus-evoked hyperpolarization (white bars; ratio between the amplitude of the stimulus-evoked hyperpolarization and the time elapsed between its beginning and its minimum), the amplitude of the hyperpolarization (light gray bars), the total duration of the stimulus-evoked hyperpolarization (dark gray bars; time elapsed between the beginning of the hyperpolarization and the return to the resting potential), and the delay (hatched bars; time between the onset of the stimulus and the beginning of the stimulus-evoked hyperpolarization). The slope of the stimulus-evoked hyperpolarization was greater, and its duration and delay to the onset were shorter, for stimulation with C3HA. Three neurons were shown to be G35-PNs; the other neuron is most likely a G35-PN but could not be characterized morphologically with certainty. Error bars indicate SE.

weakly) to c3HA tested at moderate-to-high concentrations (Fig. 8 ). These results provide evidence that the glomerular representation of c3HA is focused on G35 and not broadly distributed, but do not preclude the possibility of $\mathrm{c} 3 \mathrm{HA}$ responses in other regions of the AL (Hansson et al., 2003).

The odor-tuning properties of individual PNs also have been studied in the vertebrate OB. Although maps of identified OB glomeruli are not available, it has been shown that PNs presumably associated with the same glomerulus or in the same OB region are narrowly tuned (Buonviso and Chaput, 1990; Mori et al., 1992; Mori and Yoshihara, 1995; Nikonov and Caprio, 2004; Lin et al., 2005). Thus, our results in Manduca agree with those in vertebrates and are consistent with the hypothesis that glomeruli have relatively narrow MRRs when tested across a range of stimulus concentrations.

In several insect species including Manduca, it has been shown that the odor-evoked activity patterns revealed by calcium imaging in the main $\mathrm{AL}$ are similar for males and females (Carlsson et al., 2002; Hansson et al., 2003). Although informative, these results are difficult to interpret because the types of neurons imaged typically are not known with certainty. In the present study, we found that, in both sexes, G35-PNs have their somata in a small anterior group of AL neurons (Homberg et al., 1988), their uniglomerular arborizations in 5-6 of the 60 sexually isomorphic glomeruli (Selchow, 1998), and project to the same higher centers in the protocerebrum that are targets of other AL PNs (Fig. $2 D, K)$. Furthermore, in both sexes, G35-PNs are sensitive and preferentially responsive to c3HA (Figs. 3-6). We found no difference between males and females in the breadth of tuning of G35-PNs, at least for the small panel of odor compounds tested (Fig. 5), but the c3HA sensitivity threshold was lower in females (Fig. 4). In Manduca, the male antenna is less sensitive than the
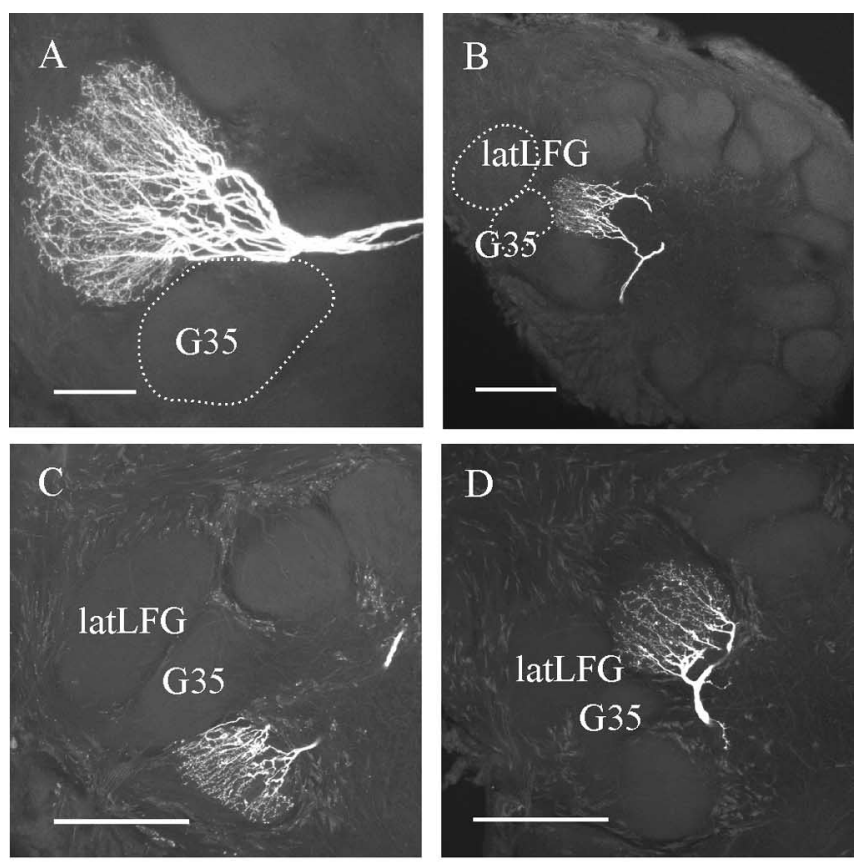

$\mathrm{E}$

F
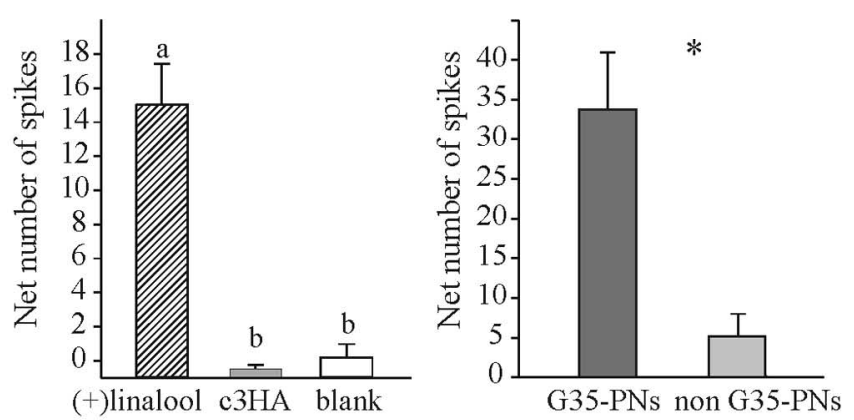

Figure 8. Morphological features and responses to $C 3 \mathrm{HA}$ of PNs arborizing in glomeruli neighboring $G 35$ in females. $A$, High-magnification confocal image of a latLFG-PN. The dotted line indicates the outline of the adjacent glomerulus $\mathrm{G} 35$. Scale bar, $40 \mu \mathrm{m}$. $\boldsymbol{B}-\boldsymbol{D}$, Examples of PNs arborizing in glomeruli neighboring G35 other than the LFGs. In these examples, the cell bodies of the PNs were in the lateral group of AL neuronal cell bodies $(\boldsymbol{B}, \boldsymbol{D})$ or in the medial group (C). The positions of the latLFG and G35 are indicated for reference. Eight such PNs in females were characterized in this study. Note that the morphology of these PNs (including others not shown) was very different from that of G35-PNs (compare with Fig. 2A-C). Scale bars, $100 \mu \mathrm{m}$. $\boldsymbol{E}$, Responses of latLFG-PNs (net number of spikes; means $\pm \mathrm{SE} ; n=7 \mathrm{PNs}$ ) to stimulation (duration, $200 \mathrm{~ms}$ ) with (+)linalool $10^{-3}$ (hatched bars), the odor compound that

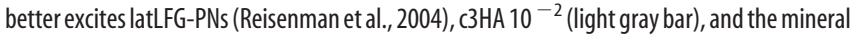
oil blank (white bar). Different lowercase letters indicate significant differences (Friedman ANOVA; $\chi^{2}=11.1 ; n=7 ; \mathrm{df}=2 ; p<0.005 ;$ all post hoc tests are significant at the 0.05 level). Responses to (+)linalool, but not to 3 HA, were statistically different from the responses to the blank. LatLFG-PNs also responded to ( \pm )linalool (King et al., 2000) but less strongly than to $(+)$ linalool (Reisenman, unpublished observations). $\boldsymbol{F}$, Responses (net number of spikes; mean \pm SE) of PNs arborizing in glomeruli neighboring $\mathrm{G} 35$ other than the LFGs (light gray bar; $n=8$ ) to stimulation with C3HA (5 and 3 PNs stimulated at $10^{-3}$ and $10^{-2}$ dilutions, respectively). The response of G35-PNs from females to stimulation with $\mathrm{C}^{\mathrm{HA}} 10^{-3}$ is shown for comparison (dark gray bar; $n=6$ ). In both cases, the responses to the blank were subtracted. The asterisk indicates significant differences between the responses of G35-PNs and non-G35PNs to stimulation with $C 3 \mathrm{HA}$ (Mann-Whitney $U$ test $Z Z=2.84 ; p<0.005$ ).

female antenna to plant volatiles, including c3HA (Fraser et al., 2003), and has fewer ORCs that respond to plant volatiles (Shields and Hildebrand, 1999). Thus, the differences in the sensitivity threshold might be attributable to differences in the number, but not in the type, of ORCs converging on the glomerulus. 
Differences in sensitivity between sexes were also described in imaging studies of afferent input in other moth species (Skiri et al., 2004). To our knowledge, the present study is the first to demonstrate rigorously, at the level of single neurons, that at least some PNs in the main olfactory pathway are morphologically and physiologically equivalent in both sexes. This suggests that at least some host-related odor compounds are processed similarly in both males and females.

The biological significance of c3HA for Manduca has not been investigated, but this odor compound is emitted by both floral and vegetative parts of host plants (Raguso et al., 2003). As adults, both sexes feed on nectar from flowers, and odor blends containing c3HA might serve as an indicator of this resource. Thus, c3HA and the G35 glomerulus (along with PNs in other sexually isomorphic glomeruli) could play a role in the location of nectar sources.

Glomeruli are considered to be functional units for olfactory coding (Buck, 1996; Hildebrand and Shepherd, 1997), and there is evidence that contiguous glomeruli interact (Kashiwadani et al., 1999; Lei et al., 2002; Nagayama et al., 2004). Inhibitory interactions are important in dynamically shaping the activity of output neurons in the OB (Friedrich and Laurent, 2004; Nagayama et al., 2004) and the AL (Vickers et al., 1998; Lei et al., 2002; Sachse and Galizia, 2002) and are thought to promote contrast enhancement of odor representations in the OB (Aungst et al., 2003; Nagayama et al., 2004). In G35-PNs, as in MGC-PNs and LPOG-PNs, odor stimulation evokes responses consisting of both excitatory and inhibitory epochs (Fig. 3). The response of female G35-PNs to $( \pm)$ linalool, which strongly activates PNs in some nearby glomeruli (Hansson et al., 2003; Reisenman et al., 2004) including the latLFG (King et al., 2000), was a slow longlasting hyperpolarization different from the fast hyperpolarization evoked by c3HA (Figs. 3, 7). The ( \pm )linalool-evoked hyperpolarization was not observed in male G35-PNs, presumably because males have no latLFG. We observed, however, that not all neighboring glomeruli display inhibitory interactions. We found that some PNs in glomeruli near G35 were not inhibited by stimulation with c3HA (Fig. 8). This agrees with results from other authors (Sachse and Galizia, 2002; Linster et al., 2005), who reported that response properties rather than spatial position determine interglomerular interactions.

Our findings support the idea that synaptic interactions between glomeruli shape their outputs. Both the $( \pm)$ linalool- and the c3HA-mediated membrane hyperpolarizations in G35-PNs appear to be mediated by multiglomerular GABAergic local interneurons (Waldrop et al., 1987; Christensen et al., 1998). Because these hyperpolarizations differ in their characteristics (Fig. 7), we expect that they are caused by different GABAergic inhibitory synaptic mechanisms (Nowycky et al., 1981; Wellis and Kauer, 1994; Palouzier-Paulignan et al., 2002; Schoppa and Urban, 2003; Murphy et al., 2005). A better understanding of such inhibitory mechanisms in Manduca is now required.

\section{References}

Angioy A, Desogus A, Barbarossa I, Anderson P, Hansson B (2003) Extreme sensitivity in an olfactory system. Chem Senses 28:279-284.

Anton S, Löfstedt C, Hansson B (1997) Central nervous processing of sex pheromones in two strains of the European corn borer Ostrinia nubilalis (Lepidoptera: Pyralidae). J Exp Biol 200:1073-1087.

Araneda R, Kini A, Firestein S (2000) The molecular receptive range of an odorant receptor. Nat Neurosci 3:1248-1255.

Aungst J, Heyward P, Puche A, Karnup S, Hayar A, Szabo G, Shipley M (2003) Centre-surround inhibition among olfactory bulb glomeruli. Nature 426:623-629.
Belluscio L, Katz L (2001) Symmetry, stereotypy, and topography of odorant representations in mouse olfactory bulbs. J Neurosci 21:2113-2122.

Berg B, Galizia C, Brandt R, Mustaparta H (2002) Digital atlases of the antennal lobe in two species of tobacco budworm moths, the oriental Helicoverpa assulta (male) and the American Heliothis virescens (male and female). J Comp Neurol 446:123-134.

Brennan P, Keverne E (2004) Something in the air? New insights into mammalian pheromones. Curr Biol 14:R81-R89.

Buck L (1996) Information coding in the vertebrate olfactory system. Annu Rev Neurosci 19:517-544.

Buonviso N, Chaput M (1990) Response similarity to odors in olfactory bulb output cells presumed to be connected to the same glomerulus: electrophysiological study using simultaneous single unit recordings. J Neurophysiol 63:447-454.

Carlsson M, Galizia C, Hansson B (2002) Spatial representation of odours in the antennal lobe of the moth Spodoptera littoralis (Lepidoptera: Noctuidae). Chem Senses 27:231-244.

Christensen TA, Hildebrand JG (1987) Male-specific, sex pheromoneselective projection neurons in the antennal lobes of the moth Manduca sexta. J Comp Physiol A Neuroethol Sens Neural Behav Physiol 160:553-569.

Christensen TA, Hildebrand JG, Tumlinson JH, Doolittle RE (1989) The sex-pheromone blend of Manduca sexta: responses of central olfactory interneurons to antennal stimulation in male moths. Arch Insect Biochem Physiol 10:281-291.

Christensen TA, Waldrop BR, Hildebrand JG (1998) Multitasking in the olfactory system: context-dependent responses to odors reveal dual GABA-regulated coding mechanisms in single olfactory projection neurons. J Neurosci 18:5999-6008.

Davis R (2004) Olfactory learning. Neuron 44:31-48.

de Bruyne M, Foster K, Carlson J (2001) Odor coding in the Drosophila antenna. Neuron 30:537-552.

Flanagan D, Mercer D (1989) An atlas and 3D reconstruction of the antennal lobes in the worker honey bee, Apis mellifera L. (Hymenoptera: Apidae). Int J Insect Morphol Embryol 18:145-159.

Fraser AM, Mechaber WL, Hildebrand JG (2003) Electroantennographic and behavioral responses of the sphinx moth Manduca sexta to host plant headspace volatiles. J Chem Ecol 29:1813-1833.

Friedrich R, Korsching S (1998) Chemotopic, combinatorial, and noncombinatorial odorant representations in the olfactory bulb revealed using a voltage-sensitive axon tracer. J Neurosci 18:9977-9988.

Friedrich R, Laurent G (2004) Dynamics of olfactory bulb input and output activity during odor stimulation in zebrafish. J Neurophysiol 91:2658-2669.

Gaillard I, Rouquier S, Pin J-P, Mollard P, Richard S, Barbanbé S, Demaille S, Giorgi D (2002) A single olfactory receptor specifically binds a set of odorant molecules. Eur J Neurosci 15:409-418.

Guerenstein PG, Yepez E, van Haren J, Williams DG, Hildebrand JG (2004a) Floral $\mathrm{CO}_{2}$ emission may indicate food abundance to nectar-feeding moths. Naturwissenschaften 91:329-333.

Guerenstein PG, Christensen TA, Hildebrand JG (2004b) Sensory processing of ambient- $\mathrm{CO}_{2}$ information in the brain of the moth Manduca sexta. J Comp Physiol A Neuroethol Sens Neural Behav Physiol 190:707-725.

Hansson B, Christensen TA, Hildebrand JG (1991) Functionally distinct subdivisions of the macroglomerular complex in the antennal lobe of the male sphinx moth Manduca sexta. J Comp Neurol 312:264-278.

Hansson B, Larsson M, Leal W (1999) Green leaf volatile-detecting olfactory receptor neurons display very high sensitivity and specificity in a scarab beetle. Physiol Entomol 24:121-126.

Hansson B, Carlsson MA, Kalinovà B (2003) Olfactory activation patterns in the antennal lobe of the sphinx moth, Manduca sexta. J Comp Physiol A Neuroethol Sens Neural Behav Physiol 189:301-308.

Hartlieb E, Anton S, Hansson B (1997) Dose-dependent response characteristics of antennal lobe neurons in the male Agrotis segetum (Lepidoptera: Noctuidae). J Comp Physiol A Neuroethol Sens Neural Behav Physiol 181:469-476.

Hildebrand JG, Shepherd GM (1997) Mechanisms of olfactory discrimination: converging evidence for common principles across phyla. Annu Rev Neurosci 20:595-631.

Homberg U, Montague RA, Hildebrand JG (1988) Anatomy of antennocerebral pathways in the brain of the sphinx moth Manduca sexta. Cell Tissue Res 254:255-281. 
Joerges J, Küttner A, Galizia C, Menzel R (1997) Representations of odours and odour mixtures visualized in the honeybee brain. Nature 387:285-288.

Johnson B, Woo C, Leon M (1998) Spatial coding of odorant features in the glomerular layer of the rat olfactory bulb. J Comp Neurol 393:457-471.

Kanzaki R, Soo K, Seki Y, Wada S (2003) Projections to higher olfactory centers from subdivisions of the antennal lobe macroglomerular complex of the male silkmoth. Chem Senses 28:113-130.

Kashiwadani H, Sasaki Y, Uchida N, Mori K (1999) Synchronized oscillatory discharges of mitral/tufted cells with different molecular receptive ranges in the rabbit olfactory bulb. J Neurophysiol 82:1786-1792.

King JR, Christensen TA, Hildebrand JG (2000) Response characteristics of an identified, sexually dimorphic olfactory glomerulus. J Neurosci 20:2391-2399.

Lei H, Christensen TA, Hildebrand JG (2002) Local inhibition modulates odor-evoked synchronization of glomerulus-specific output neurons. Nat Neurosci 5:557-565.

Lin D, Zhang S-Z, Block E, Katz L (2005) Encoding social signals in the mouse main olfactory bulb. Nature 434:470-477.

Linster C, Sachse S, Galizia C (2005) Computational modeling suggests that response properties rather than spatial position determine connectivity between olfactory glomeruli. J Neurophysiol 93:3410-3417.

Loughrin J, Hamilton-Kemp T, Andersen R, Hildebrand D (1990) Headspace compounds from flowers of Nicotiana tabacum and related species. J Agric Food Chem 38:455-460.

Ma M, Shepherd G (2000) Functional mosaic organization of mouse olfactory receptor neurons. Proc Natl Acad Sci USA 97:12869-12874.

Masante-Roca I, Gadenne C, Anton S (2005) Three-dimensional antennal lobe atlas of male and female moths, Lobesia botrana (Lepidoptera: Tortricidae) and glomerular representation of plant volatiles in females. J Exp Biol 208:1147-1159.

Mombaerts P, Wang F, Dulac C, Chao S, Nemes A, Mendelsohn M, Edmondson J, Axel R (1996) Visualizing an olfactory sensory map. Neuron 87:675-686.

Mori K, Yoshihara Y (1995) Molecular recognition and olfactory processing in the mammalian olfactory system. Prog Neurobiol 45:585-619.

Mori K, Mataga N, Imamura K (1992) Differential specificities of single mitral cells in rabbit olfactory bulb for a homologous series of fatty acid odor molecules. J Neurophysiol 67:786-789.

Murphy G, Darcy D, Isaacson J (2005) Intraglomerular inhibition: signaling mechanisms of an olfactory microcircuit. Nat Neurosci 8:354-364.

Nagayama S, Takahashi Y, Yoshihara Y, Mori K (2004) Mitral and tufted cells differ in the decoding manner of odor maps in the rat olfactory bulb. J Neurophysiol 91:2532-2540.

Ng M, Roorda R, Lima S, Zemelman B, Morcillo P, Miesenbock G (2002) Transmission of olfactory information between three populations of neurons in the antennal lobe of the fly. Neuron 36:463-474.

Nikonov A, Caprio J (2004) Odorant specificity of single olfactory bulb neurons to amino acids in the channel catfish. J Neurophysiol 92:123-134.

Nowycky M, Mori K, Shepherd G (1981) GABAergic mechanisms of dendrodendritic synapses in isolated turtle olfactory bulb. J Neurophysiol 46:639-648.

Palouzier-Paulignan B, Duchamp-Viret P, Hardy A, Duchamp A (2002) $\mathrm{GABA}_{\mathrm{B}}$ receptor-mediated inhibition of mitral/tufted cell activity in the rat olfactory bulb: a whole-cell patch-clamp study in vitro. Neuroscience 111:241-250.

Perez-Orive J, Mazor O, Turner G, Cassenaer S, Wilson R, Laurent G (2002) Oscillations and sparsening of odor representations in the mushroom body. Science 297:359-365.

Raguso R, Henzel C, Buchmann S, Nabhan G (2003) Trumpet flowers of the Sonoran desert: floral biology of Peniocereus cacti and sacred Datura. Int J Plant Sci 164:877-892.

Reisenman CE, Christensen TA, Francke W, Hildebrand JG (2004) Enantioselectivity of projection neurons innervating identified olfactory glomeruli. J Neurosci 24:2602-2611.

Rospars JP, Hildebrand JG (1992) Anatomical identification of glomeruli in the antennal lobes of the male sphinx moth Manduca sexta. Cell Tissue Res 270:205-227.

Rospars JP, Hildebrand JG (2000) Sexually dimorphic and isomorphic glomeruli in the antennal lobes of the sphinx moth Manduca sexta. Chem Senses 25:119-129.

Røstelien T, Borg-Karlson A-K, Fäldt J, Jacobsson U, Mustaparta H (2000) The plant sesquiterpene germacrene D specifically activates a major type of antennal receptor neuron of the tobacco budworm moth Heliothis virescens. Chem Senses 25:141-148.

Rubin B, Katz L (1999) Optical imaging of odorant representations in the mammalian olfactory bulb. Neuron 23:499-511.

Sachse S, Galizia G (2002) Role of inhibition for temporal and spatial odor representation in olfactory output neurons: a calcium imaging study. J Neurophysiol 87:1106-1117.

Sadek M, Hansson B, Rospars J, Anton S (2002) Glomerular representation of plant volatiles and sex pheromones components in the antennal lobe of the female Spodoptera littoralis. J Exp Biol 205:1363-1376.

Schoppa N, Urban N (2003) Dendritic processing within olfactory bulb circuits. Trends Neurosci 26:501-506.

Selchow KI (1998) Processing of plant-associated odors by a subset of projection neurons in the antennal lobe of the female moth Manduca sexta. $\mathrm{PhD}$ thesis, University of Arizona.

Shields V, Hildebrand J (1999) Fine structure of antennal sensilla of the female sphinx moth, Manduca sexta (Lepidoptera: Sphingidae). II. Auriculate, coeloconic, and styliform complex sensilla. Can J Zool 77:302-313.

Shields V, Hildebrand J (2001) Responses of a population of antennal olfactory receptor cells in the female moth Manduca sexta to plant-associated volatile organic compounds. J Comp Physiol A Neuroethol Sens Neural Behav Physiol 186:1135-1151.

Skiri H, Galizia C, Mustaparta H (2004) Representation of primary plant odorants in the antennal lobe of the moth Heliothis virescens using calcium imaging. Chem Senses 29:253-267.

Stranden M, Røstelien T, Liblikas I, Almaas T, Borg-Karlson A-K, Mustaparta $\mathrm{H}$ (2003) Receptor neurons in three heliothine moths responding to floral and inducible plant volatiles. Chemoecology 13:143-154.

Suh G, Wong A, Hergarden A, Wang J, Simon A, Benzer S, Axel R, Anderson D (2004) A single population of olfactory sensory neurons mediates an innate avoidance behaviour in Drosophila. Nature 431:854-859.

Takahashi Y, Kurosaki M, Hirono S, Mori K (2004) Topographic representation of odorant molecular features in the rat olfactory bulb. J Neurophysiol 92:2413-2427.

Vickers NJ, Christensen TA, Hildebrand JG (1998) Combinatorial odor discrimination in the brain: attractive and antagonist odor blends are represented in distinct combinations of uniquely identifiable glomeruli. J Comp Neurol 400:35-56.

Wachowiak M, Cohen L (2003) Correspondence between odorant-evoked patterns of receptor neuron input and intrinsic optical signals in the mouse olfactory bulb. J Neurophysiol 89:1623-1639.

Waldrop B, Christensen TA, Hildebrand JG (1987) GABA-mediated synaptic inhibition of projection neurons in the antennal lobes of the sphinx moth, Manduca sexta. J Comp Physiol A Neuroethol Sens Neural Behav Physiol 161:23-32.

Wang J, Wong A, Flores J, Vosshall L, Axel R (2003) Two-photon calcium imaging reveals an odor-evoked map of activity in the fly brain. Cell 112:271-282.

Wellis D, Kauer J (1994) GABAergic and glutamatergic synaptic input to identified granule cells in salamander olfactory bulb. J Physiol (Lond) 475:419-430.

Wilson R, Turner G, Laurent G (2004) Transformation of olfactory representations in the Drosophila antennal lobe. Science 303:366-370.

Xu F, Liu N, Kida I, Rothman D, Hyder F, Shepherd G (2003) Odor maps of aldehydes and esters revealed by functional MRI in the glomerular layer of the mouse olfactory bulb. Proc Natl Acad Sci USA 100:11029-11034.

Zar J (1999) Biostatistical analysis. Upper Saddle River, NJ: Prentice-Hall.

Zhao H, Ivic L, Otaki J, Hashimoto M, Mikoshiba K, Firestein S (1998) Functional expression of a mammalian odorant receptor. Science 279: 237-242. 